\title{
Evaluation of thermal remote sensing indices to estimate crop evapotranspiration coefficients
}

\author{
Emily G. Kullberga, ${ }^{\mathrm{a}, \mathrm{b}}$, Kendall C. DeJonge ${ }^{\mathrm{c}, *}{ }^{\text {José L. Chávez }}$, \\ ${ }^{a}$ Dept. of Civil and Enviornmental Engineering, Colorado State University, Fort Collins, CO \\ 80523 USA \\ ${ }^{\mathrm{b}}$ Aqua Engineering Inc., Fort Collins CO 80525 \\ ${ }^{c}$ USDA-ARS, Water Management Systems Research Unit, Fort Collins, CO 80526 USA \\ * corresponding author. \\ Address: 2150 Centre Ave, Bldg. D Ste. 320, Fort Collins CO 80526 \\ Tel.: +01 970 492-7417; fax: +01970 492-7408. \\ E-mail address: Kendall.DeJonge@ars.usda.gov
}

\begin{abstract}
Remotely sensed data such as spectral reflectance and infrared canopy temperature can be used to quantify crop canopy cover and/or crop water stress, often through the use of vegetation indices calculated from the near-infrared and red bands, and stress indices calculated from the thermal wavelengths,. Standardized dual crop coefficient methods calculate both a non-stressed transpiration coefficient $\left(K_{c b}\right)$ that is related to canopy cover, and a stress or transpiration reduction coefficient $\left(K_{s}\right)$ that can be related to soil water deficit or other stress factors (e.g. disease). This study compares several remote sensing methods to determine $K_{c b}$ and
\end{abstract}


$K_{s}$ and resulting evapotranspiration (ET) in a deficit irrigation experiment of corn (Zea mays L.) near Greeley, Colorado. Three methods were used to calculate $K_{c b}$ (tabular, normalized difference vegetation index - NDVI, and canopy cover). Four canopy temperature based methods were used to calculate $K_{S}$ : Crop Water Stress Index - CWSI, Canopy Temperature Ratio Tcratio, Degrees Above Non-Stressed - DANS, Degrees Above Canopy Threshold - DACT. Crop ET predicted by these methods was compared to observation and water balance based ET measurements. Thermal indices DANS and DACT were calibrated to convert to $K_{s}$. Results showed that stress coefficient methods with less data requirements such as DANS and DACT are responsive to crop water stress as demonstrated by low RMSE of ET calculations, comparable to more data intensive methods such as CWSI. Results indicate which remote sensing methods are appropriate to use given certain data availability and irrigation level, in addition to providing an estimation of the associated error in ET.

Keywords:

Canopy temperature

Crop coefficient

Crop water stress index

DANS index

DACT index 


\section{LIST OF SYMBOLS AND ABBREVIATIONS}

DACT degrees above canopy threshold $\left({ }^{\circ} \mathrm{C}\right)$

DANS degrees above non-stressed canopy $\left({ }^{\circ} \mathrm{C}\right)$

$D_{r} \quad$ root zone depletion, or soil water deficit (mm)

DP $\quad$ deep percolation $(\mathrm{mm})$

ET evapotranspiration ( $\mathrm{mm} /$ day)

$E T_{c} \quad$ crop evapotranspiration (mm/day)

$E T_{r} \quad$ alfalfa-based reference evapotranspiration (mm/day)

$f_{c} \quad$ fractional vegetation cover

GW ground water input (mm)

I total net irrigation amount applied (mm)

IRT infrared thermometer $\left({ }^{\circ} \mathrm{C}\right)$

$K_{c} \quad$ crop coefficient

$K_{c b} \quad$ basal crop coefficient

$K_{s} \quad$ stress crop coefficient

LIRF Limited Irrigation Research Farm

MAD maximum allowable depletion ( $\mathrm{mm}$ )

NDVI normalized difference vegetation index

$P \quad$ effective precipitation (mm)

RAW readily available water $(\mathrm{mm})$

RH relative humidity (\%)

$R_{n i r} \quad$ reflectance in the near infrared band 
$R_{\text {red }} \quad$ reflectance in the red band

SWD soil water deficit (mm)

TAW total available water $(\mathrm{mm})$

TDR time domain reflectometer

$T_{c} \quad$ crop canopy temperature $\left({ }^{\circ} \mathrm{C}\right)$

$T_{c N S} \quad$ non-stressed canopy temperature $\left({ }^{\circ} \mathrm{C}\right)$

$T_{\text {critical }} \quad$ critical canopy temperature threshold $\left({ }^{\circ} \mathrm{C}\right)$

VI vegetation index

VWC volumetric water content $\left(\mathrm{m}^{3}\right)$ 


\section{Introduction}

As climate change and population growth both place unprecedented demand on the

3 world's finite fresh water supply, competition among various water users (e.g. irrigation,

4 recreation, industry, and municipal) is likely to increase. As the largest consumptive water user,

5 irrigated agriculture experiences pressure to reduce water use while maintaining high yields

6 (Allen et al., 2007). An additional challenge is presented by climate change which may alter

7 historical precipitation patterns and increase droughts (Walthall et al., 2012). In order to continue

8 to sustain a rapidly growing population with vulnerable and limited water resources, producers

9 must be adequately prepared to adapt irrigated agriculture practices.

10 One strategy under current reasearch is regulated deficit irrigation where irrigation

11 applications are less than the full crop water requirement. Through regulated deficit irrigation,

12 high water productivity is achieved by careful monitoring of crop water status and timing of

13 irrigation applications. Deficit irrigation ideally results in no water losses due to deep percolation

14 because it never fully replenishes the crop root zone. In addition, evaporation losses may be

15 reduced by less frequent irrigation applications. Additionally, crops often have varying water

16 stress sensitivity at different growth stages, which can inform the producer as to when placing

17 more stress on the plant will have a smaller impact on yield (Fereres and Soriano, 2007).

Many farms have been historically over-irrigated, often sacrificing irrigation efficiency

19 for yield stability, although there may still be harmful effects of over-irrigating such as

20 waterlogging and salinity (Montoro et al., 2011). When irrigation water becomes expensive or

21 limited the producers will move from a stress prevention approach to a stress management

22 approach, and deficit irrigation during critical growth periods may be an effective way to

23 maintain production while decreasing water use. A review on deficit irrigation by Fereres and 
24 Soriano (2007) affirms the idea that applying less than full irrigation can increase water

25 productivity and even farmers' profits. They noted that successful deficit irrigation strategies are

26 typically found within situations that permit the application of at least $60 \%$ of crop water

27 requirement and are designed based on crop drought sensitivity during each development stage.

28 Many other recent studies have explored the outcomes of deficit irrigation with similar results

29 (Conaty, 2010; DeJonge et al., 2011; Fereres and Soriano, 2007; Kang et al., 2000; Taghvaeian

30 et al., 2012).

31 Managed deficit irrigation relies on quantification of crop water use, or

32 evapotranspiration (ET). Standardized methods of measuring and estimating ET assume fully

33 irrigated conditions and therefore do not accurately estimate water use if soil water deficit

34 conditions limit ET. Thus, methods that are sensitive to crop development and stress are

35 necessary during droughts or under deficit irrigation. Reference evapotranspiration is the ET

36 from a reference crop (12 cm high clipped grass or $50 \mathrm{~cm}$ tall full-cover alfalfa) and therefore

37 incorporates the effects of weather into the ET estimate (ASCE, 2005). To use the reference ET

38 calculation method to estimate crop ET, the ratio of a cropped and reference surface is combined

39 into a crop coefficient according to ASCE (2005) as:

$$
E T_{c}=E T_{r} \cdot K_{c}
$$

40 where $K_{c}$ is the crop coefficient, $E T_{c}$ is crop ET (mm), $E T_{r}$ is alfalfa or tall reference surface ET

41 (mm). The effect of microclimate on ET is described by $E T_{r}$ and the properties of the crop which

42 affect ET are quantified by $K_{c}$ (Allen et al., 1998). This method can be used to calculate the ET

43 of a crop under "standard" (i.e. non-stressed) conditions, but cannot directly estimate the ET of a

44 water stressed crop. Allen et al. (1998) separated the crop coefficient into evaporation and plant 
45 transpiration components, the latter which included a stress coefficient for soil water limiting

46 conditions $\left(K_{s}\right)$ shown as:

$$
E T_{c}=\left(K_{c b} K_{s}+K_{e}\right) E T_{r}
$$

47 where $K_{c b}$ is the basal crop coefficient representing transpiration when the plant is under no

48 stress, and $K_{e}$ is the evaporation coefficient.

49 The basal crop coefficient $K_{c b}$ can be obtained from published tabular values such as

50 those listed for a short crop reference in Allen et al. (1998) and typically has a trapezoidal shape

51 that has a strong relationship with canopy cover. A source of error with tabulated values is that

52 corn under different environmental and management conditions does not grow at the same rates.

53 Basing the crop coefficient on growing degree days may be more accurate, but even this method

54 can vary from with regional, management, and climatic variability. Water stress may further alter

55 growth rates based on timing of water deficit or water application, and Mahan et al. (2014)

56 suggest canopy temperature should be considered along with growing degree days to improve

57 the utility of heat units. Alternately, canopy cover or reflectance data can be used to estimate $K_{c b}$

58 throughout the season.

Reflectance-based basal crop coefficient $\left(K_{c b}\right)$ methods developed by Neale et al. (1989)

60 and Bausch (1993) have been used to improve irrigation scheduling of corn. Reflectance-based

61 basal crop coefficient methods rely on remote sensing data to calculate a vegetation index and a

62 linear relationship between the vegetation index and the reflectance-based crop coefficient. One

63 of the most commonly used vegetation indices is the normalized difference vegetation index

64 (NDVI):

$$
\mathrm{NDVI}=\frac{R_{\text {nir }}-R_{\text {red }}}{R_{\text {nir }}+R_{\text {red }}}
$$


65 where $R_{\text {nir }}$ is reflectance in the near infrared band and $R_{\text {red }}$ is reflectance in the red band. Using

66 NDVI, Neale et al. (1989) developed a relationship for corn in Greeley, Colorado, to determine

67 the basal crop coefficient $K_{c b}$ from remotely sensed data (NDVI). A more recent development in

68 the estimation of actual crop coefficients was the work of Trout et al. (2008) and Johnson and

69 Trout (2012) which showed that $K_{c b}$ can be estimated from fractional vegetation cover $\left(f_{c}\right)$.

70 Johnson and Trout (2012) also demonstrated that if $f_{c}$ measurements are not available, NDVI can

71 be used to estimate $f_{c}$ by

$$
f_{c}=1.26(\mathrm{NDVI})-0.18
$$

72 Once $f_{c}$ has been obtained either through Eq. (4) or more directly by image processing, the basal

73 crop coefficient can be estimated as

$$
K_{c b}=1.13 f_{c}+0.14
$$

74 Reflectance-based crop coefficients assess current crop conditions instead of assuming the crop

75 is under "standard" conditions, an advantage over tabular values. Whether measured vegetation

76 indices or fractional vegetation cover is used to calculate $K_{c b}$, it will determine $E T_{c}$ better than a

77 tabulated crop coefficient because it reflects not only the actual growth stage of the crop but also

78 reductions in canopy cover due to previous stresses.

79 The dual crop coefficient approach reduces the stress coefficient $K_{s}$ when the soil water

80 content is less than the level of maximum allowable depletion (MAD) (Allen et al., 1998). $K_{s}$

81 represents the fraction of potential transpiration rate that a crop is experiencing reduced from 1.0

82 according to the level of water stress. Thus, under soil water limiting conditions, $K_{s}$ will be less

83 than $1 . K_{s}$ can be as low as 0 in the case that the plant can no longer extract water from extremely

84 dry soil. $K_{s}$, according to the Allen et al. (1998) FAO-56 soil water depletion method, is

85 calculated by: 


$$
K_{s}=\frac{T A W-D_{r}}{T A W-R A W}
$$

87 (mm), and $R A W$ is readily available water $(\mathrm{mm}) . R A W$ is the portion of $T A W$ which a crop can 95 deficit $\left(D_{r, i-1}\right)$.

where $T A W$ is the total available soil water in the root zone $(\mathrm{mm}), D_{r}$ is the root zone depletion extract from the root zone without water stress impacts on ET, growth, and yield.

Daily $E T_{c}$ must be calculated in order to determine the soil water deficit through the water balance method. The water balance method uses inputs of $E T_{c}(\mathrm{~mm})$, deficit for the day of interest $\left(D_{r, i}, \mathrm{~mm}\right)$, effective precipitation $(P, \mathrm{~mm})$, net irrigation $(I, \mathrm{~mm})$, deep percolation $(D P$, $\mathrm{mm})$, and ground water flux $(G W, \mathrm{~mm})$ to calculate daily soil water deficits (Allen et al., 2007):

$$
D_{r, i}=D_{r, i-1}+E T_{c^{-}} P-I+D P-G W
$$

In the absence of a high water table, $G W$ inputs are assumed negligible. $D_{r, i}$ is calculated by taking into account the cumulative effect of the daily inputs and outputs on the previous day's

One caveat of the water balance method is that reliable spatially and temporally variable soil water content data are expensive and difficult to obtain. Plant-based methods to assess plant stress and ET reductions may have advantages in ease of use and of measuring stress in multiple locations within a field so a more accurate average stress level can be determined. Remotelycollected data such as spectral reflectance, fractional vegetation cover, and canopy temperature can indicate plant water stress (Maes and Steppe, 2012), are non-destructive, and have the capability to be applied on various spatial and temporal scales. Land surface multispectral reflectance and crop canopy temperature information from remote sensing data have been used to quantify crop water stress through the use of different temperature indices calculated from the thermal waveband (Jackson et al., 1981; Idso, 1982; O’Shaughnessy and Evett, 2010; Bausch et 
107 the near-infrared band and the red band (Neale et al., 1989; Bausch, 1993; DeJonge et al., 2016). Remotely sensed crop canopy temperature can be a simple indicator of crop water stress.

109 If there is adequate water in the root zone, available atmospheric energy will be used by the plant 110 for evaporating water (transpiration). Once the water which the crop can easily extract $(R A W)$

111 has been depleted from the soil profile, available energy will instead cause heating of the plant

112 (Maes and Steppe, 2012). Clawson and Blad (1982) were some of the earliest to demonstrate use

113 of infrared thermometry for scheduling irrigation: their canopy temperature-scheduled deficit

114 plot had only a 5\% yield reduction compared to full irrigation plot scheduled with neutron probe

115 data. Clawson and Blad concluded that crop canopy temperature data best indicates the plant

116 water stress severity by identifying canopy temperature difference between a stressed plot and a

117 fully-irrigated reference crop. Other recent studies have looked at infrared thermometry in

118 northern Colorado (Bausch et al., 2011; DeJonge et al., 2015; Taghvaeian et al., 2012, 2014a, $1192014 b)$.

120 Jackson et al. (1981) demonstrated the potential of using infrared thermometers for 121 irrigation scheduling by devising the CWSI method, which relies on the linear relationship 122 between the difference between canopy and air temperature and the vapor pressure deficit - thus 123 is a function of canopy temperature, air temperature, relative humidity, and user-defined baseline 124 parameters. CWSI varies from 0 (no stress) to 1 (maximum stress). CWSI, as well as all other 125 canopy temperature methods, are less reliable when full cover has not yet been attained because 126 canopy temperature measurements inevitably incorporate soil temperature (Jackson et al., 1981). 127 Nonetheless, CWSI irrigation scheduling has proven to have the potential to be effective and to 128 reduce water consumption. CWSI method has been widely used in deficit irrigation studies and 
129 is considered a standard for irrigation scheduling under deficit irrigation (Alderfasi and Nielsen,

130 2001; Irmak et al., 2000; Taghvaeian et al., 2012; Zia et al., 2011). Because Jackson et al. (1981)

131 showed that CWSI is inversely related to the water use of the crop under consideration, an

132 alternative to calculating the stress coefficient $K_{s}$ from soil water data (Eq. 3) $K_{s}$ can also be

133 calculated from CWSI as:

$$
K_{S}=(1-\mathrm{CWSI})
$$

While CWSI has been researched for several decades, the data requirements besides

135 canopy temperature (namely air temperature and VPD) can be restrictive to practical application.

136 An alternative method to evaluate water stress that only requires crop canopy temperature was

137 proposed by Bausch et al. (2011):

$$
K_{s}=T_{\text {cratio }}=\frac{T_{c N S}}{T_{c}}
$$

138 where $\mathrm{T}_{\text {cratio }}$ is a stress coefficient proposed to be a surrogate for the water stress coefficient $K_{s}$

139 from FAO-56 (Allen et al., 1998), $T_{c}$ is the measured canopy temperature of a crop under water

140 stress and $T_{c N S}$ is the temperature of a fully irrigated, non-stressed canopy. This temperature ratio

141 was found to be capable of quantitatively monitoring water stress and potentially be used in the

142 place of the water stress coefficient when soil water measurements are not available (Bausch,

143 2011). However, this method does have drawbacks in that the parameter would typically not

144 approach zero under high stress where $T_{c} \gg T_{c N S}$, and also that there are scaling issues

145 dependent on the temperature scale used (DeJonge et al., 2015).

146 Other canopy temperature-based methods have recently been proposed which can

147 indicated crop water stress, but like the $T_{\text {cratio }}$ method of Bausch et al. (2011) require less inputs

148 than CWSI. Degrees Above Non-Stressed canopy (DANS, Taghvaeian et al., 2014a) is the

149 difference between canopy temperatures of stressed and non-stressed plants 


$$
\mathrm{DANS}=\min \left(0, T_{c}-T_{c N S}\right)
$$

150 where $T_{c}$ is the canopy temperature for the crop condition of interest and $T_{C N S}$ is the canopy

151 temperature at the same time of a nearby fully irrigated crop, which ideally is the same variety

152 and growth stage. As discussed in DeJonge et al. (2015), the $T_{\text {cratio }}$ and DANS methods, which

153 rely on a nonstressed reference, require numerically that $T_{c N S} \leq T_{c}$ to ensure that $T_{\text {cratio }} \leq 1$ and

154 DANS $\geq 0$. To ensure this requirement, $T_{c N S}$ was chosen as the lowest observed $T_{c}$ at the given

155 timestamp, including all treatments. Advantages and risks of this technique are discussed in

156 more detail in DeJonge et al. (2015).

157 Another similar parameter is Degrees Above Canopy Threshold (DACT, DeJonge et al., 158 2015), which is similar to DANS except that the canopy temperature threshold ( $\left.T_{\text {critical }}\right)$ is simply

159 a known constant for a given crop

$$
\mathrm{DACT}=\max \left(0, T_{c}-T_{\text {critical }}\right)
$$

160 It is assumed that if the crop canopy is less than $T_{\text {critical }}$, it is not under stress and DACT will

161 return a value of 0 . Temperature threshold $\left(T_{\text {critical }}\right)$ of $28^{\circ} \mathrm{C}$ for corn represents the crop

162 temperature at which photosynthetic enzyme activity is at its highest (Burke, 1996). This

163 threshold has been used in other studies in conjunction with the time temperature threshold

164 (TTT) method which similarly evaluates the amount of time the canopy temperature is above the 165 threshold (O'Shaughnessy et al., 2010).

166 DACT has the advantage of only requiring a single canopy temperature measurement, 167 opposed to DANS which also requires canpy temperature of a fully irrigated crop. Both DACT 168 and DANS suggest spot measurements to be taken around solar noon on sunny days, similar to 169 CWSI, and have been found to have a comparable ability to monitor water stress (DeJonge et al., 
170 2015). However, no study to date has directly converted the DANS or DACT indices into a stress

171 coefficient $\left(K_{s}\right)$ and compared predicted ET with observed datasets.

172 The overall goal of this study is to compare the performance of several water stress

173 coefficient methods to estimate evapotranspiration of corn in Northeastern Colorado under

174 various levels of deficit irrigation. Specific objectives are:

175 1. Use two years of data from a corn field experiment near Greeley, Colorado to calibrate 176 conversion of DANS and DACT indices into stress coefficients $\left(K_{s}\right)$.

1772 2. Use two different years of data from the same experiment to estimate daily $E T_{c}$, through a 178 combination of three methods to determine the basal crop coefficient $K_{c b}$ (tabular, NDVI, 179 canopy cover) and four methods to determine the stress coefficient $K_{s}$ (CWSI, $\mathrm{T}_{\text {cratio, }}$, 180 DANS, DACT).

181 3. Compare accuracy of each method by computing mean biased error (MBE) and root 182 183 mean squared error (RMSE) of results as compared to $E T_{c}$ calculated by soil water balance.

4. Provide suggestions of appropriate methods for evaluating water use and monitoring stress under different levels of irrigation and data availability.

187 2. Methods

\subsection{Site and data description}

The field study was conducted from 2010 through 2013 at a Limited Irrigation Research

190 Farm (LIRF) near Greeley, $\mathrm{CO}\left(40^{\circ} 26^{\prime} \mathrm{N}, 104^{\circ} 38^{\prime} \mathrm{W}\right.$, and $1428 \mathrm{~m}$ elevation). LIRF is a

191 facility operated and maintained by the United States Department of Agriculture (USDA)

192 Agricultural Research Service Water Management Research Unit (ARS-WMRU). LIRF is 
193 irrigated with a pressurized surface drip system. Treatments received irrigation corresponding to 194 percentage of full (100\%) crop ET. In 2010 and 2011 there were 3 irrigation treatments and in 1952012 and 2013 there were 7 irrigation treatments used for this study, with 4 replications of each 196 treatment (Table 1). In all years Treatment 1 received $100 \%$ of $E T_{c}$, fully satisfying water 197 requirements through the entire growing season. In 2010 and 2011, deficit irrigation treatments 198 aimed for $E T_{c}$ to be proportional to Treatment 1 throughout the season. In 2012 and 2013, deficit 199 irrigation treatments aimed for $E T_{c}$ to be proportional to Treatment 1 during vegetative and 200 maturity growth stages, but allocated $100 \% E T_{c}$ during sensitive reproductive growth stages. In 201 order to have multiple independent years of data to calibrate and validate DANS and DACT 202 index equations, the 2010 and 2011 growing seasons of corn were chosen for calibration. For 203 evaluation and comparison of methods, 2012 and 2013 data were used. Table 1 displays the 204 irrigation treatment structure of the plots used for this study, with first number being percent ET 205 applied during vegetative stage and second number being percent ET applied during maturation 206 growth stage.

207 Permanent stationary IRTs (model: SI-121, Apogee Instruments ${ }^{1}$, Inc., Logan, Utah, 208 USA) took continuous readings of canopy temperature (measured every 5 seconds and averaged 209 over 30 minute intervals). IRT measurements and subsequent $T_{c^{c}}$-based indices used in this study 210 were all taken at 1400h (approximate time of peak stress), unless indicated otherwise. To test the 211 overall utility and robustness of all of the methods, data was not sorted for cloud cover. IRTs 212 were attached to telescoping posts and adjusted throughout growing season to maintain a height

\footnotetext{
${ }^{1}$ Mention of trade names or commercial products in this manuscript is solely for the purpose of providing specific information, and does not imply recommendation or endorsement by the U.S. Department of Agriculture or the Agricultural Research Service of any product or service to the exclusion of others that may be suitable.
} 
213 of approximately 0.8 meters above the canopy. In order to minimize the background effect of the 214 soil, IRTs were installed at an angle $23^{\circ}$ below horizon and $45^{\circ}$ east from north (rows were in 215 north/south orientation). Spectral reflectance measurements were taken weekly near solar noon 216 under conditions of minimal cloud cover with Exotech (100BX-T, Exotech Inc., Gaithersburg, 217 MD) sensors in 2010-2011 or Skye (SKR1850ND, Skye Instruments, Llandrindod Wells, UK)

218 sensors in 2012-2013. Canopy cover, or fractional vegetation cover $\left(f_{c}\right)$, was estimated by 219 processing nadir RGB (red/green/blue) images using software that identifies green pixels 220 (vegetation) and non-green pixels (soil), and outputs VF for each image. IRT readings when $f_{c}<$ $22180 \%$ were omitted from analysis. Soil water content measurements were taken with a neutron 222 probe (CPN-503DR Hydroprobe, InstroTec, San Francisco, CA) at depths of $30 \mathrm{~cm}$ to $105 \mathrm{~cm}$ 223 from the surface before and after irrigation events, approximately 2 or 3 times a week. Accuracy 224 ranges for neutron probe measurements are typically reported between 0.01 and $0.024 \mathrm{~mm} / \mathrm{m}$ 225 according to Huisman et al. (2003). Evett et al. (2006) found that with field calibration, as was 226 done for these measurements, all RMSE values were less than $0.01 \mathrm{~m}^{3} \mathrm{~m}^{-3}$. The neutron probe 227 relies on the gravimetric method for its volumetric water concent calibration, so its accuracy is 228 closely related to that of the gravimetric sampling method (Topp and Ferré, 2002). A time 229 domain reflectometer (TDR) (miniTrase, 6050X3K1) was used to measure the volumetric water 230 content within the top $15 \mathrm{~cm}$ of the soil profile. . Meteorological data were obtained from the 231 LIRF onsite weather station (CoAgMet Weather Station Network, Station GLY04,

232 www.coagmet.com), located on a 0.4 ha grass plot adjacent to the LIRF research fields. Average 233 daily weather parameters and total rainfall amounts during study periods (July 7 - September 7) 234 in 2010 through 2013 are presented in Table 2. Total precipitation values can be compared to the 235 long term total precipitation average for this time period of $70.7 \mathrm{~mm}$ in order to infer whether a 
236 period was above or below average. $E T_{r}$, or reference ET from a tall reference crop, was used in

237 this study because alfalfa has historically been the reference crop for Colorado and better

238 captures the climatic effects such as wind on ET of tall crops.

239 2.2. Estimation of crop ET

240 Crop ET was calculated using measured soil water content data and a water balance

241 procedure. Approximately 2 to 3 times per week throughout the growing season, soil water

242 content measurements were subtracted from the field capacity to obtain soil water deficit (mm).

243 On days where soil water deficit was not measured, a water balance method was applied by

244 using a spreadsheet into which the irrigation events and effective precipitation events were input,

245 deep percolation was calculated, and finally soil water deficit was calculated as described in Eq.

246 7. Estimates of volumetric water content at field capacity for each depth (0 to 150, 150 to 450 ,

247 and 750 to $1050 \mathrm{~mm}$ ) of each treatment were measured using pressure plate analysis and later

248 adjusted with SWC observations following irrigation and rainfall events. Root zone depth was

249 modeled throughout the season based on observations of soil water uptake and used in order to

250 find the total soil water deficit of the root zone. If the total deficit of the root zone was calculated

251 to be negative, then the deficit value is assumed to be zero and the excess water is assumed to be

252 lost to deep percolation. $E T_{r}$ from the onsite weather station and $K_{c b}$ based on canopy cover are

253 utilized to predict $E T_{c}$.

$254 \quad$ 2.3. Basal crop coefficient $K_{c b}$

255 Three methods to calculate $K_{c b}$ were used in this study. The first method was tabular $K_{c b}$

256 which was determined by constructing a curve using crop-specific values for planting and full

257 cover dates with the method specified by the ASABE Monograph for alfalfa reference ET (Allen

258 et al., 2007). The method of obtaining $K_{c b}$ from fractional cover data represents the second $K_{c b}$ 
method used in this study, a linear interpolation between tabular values of initial $K_{c b}(0.15)$ and

260 mid-season $K_{c b}(0.96)$ at $f_{c} \geq 0.8$. The third method chosen was to estimate $f_{c}$ from NDVI (Eq 4)

261 to represent situations where direct $f_{c}$ measurements are not available, and $K_{c b}$ was calculated

262 using Eq. 5. Quality of the canopy cover and NDVI data obtained and the accuracy of the Eqs. 4

263 and 5 will govern which method performs best. By applying all three methods to obtain basal

264 crop coefficient values, the absolute and relative accuracies can be observed within the context

265 of this study.

\section{2.4. DANS and DACT calibration to $K_{s}$}

267 Stress detection methods DANS and DACT required transformation in order to be used

268 in the place of a $K_{s}$ value. For this evaluation of DANS and DACT as stress coefficients, Eq. (12)

269 and (13) were calibrated with data from LIRF 2010 and 2011 corn growing season. This causes

270 them to differ from the other methods in this study by containing an empirically calibrated

271 component while other methods were not calibrated for local conditions; however, as described

272 earlier both CWSI (Eqn. 8) and $T_{\text {cratio }}$ (Eqn. 11) are assumed to have simple and previously

273 established transformations to $K_{s}$. This is a preliminary study to evaluate the feasibility of

274 applying these simple measures of stress to improve deficit irrigation water management with

275 limited data.

276 Because temperature indices DANS and DACT both have units of ${ }^{\circ} \mathrm{C}$ and a theoretical 277 scale of zero for no stress and an unbounded positive number for high stress, they need to be 278 normalized for use as stress coefficients. An independent dataset of both temperature data and 279 FAO-56 method water stress coefficients $\left(K_{s}\right)$ were used to calibrate these methods before use in 280 this study, so that the $\mathrm{ET}_{\mathrm{c}}$ found by using a $K_{s}$ from DANS or DACT would closely match $\mathrm{ET}_{\mathrm{c}}$ 
281 found by the water balance. LIRF 2010 and 2011 corn data were used with the following

282 equation

$$
K_{S}=\max \left(1-\frac{\mathrm{DANS}}{x}, 0\right)
$$

283 where $K_{s}$ is the DANS-based stress coefficient, and $x$ is a variable optimized to reduce the RMSE

284 between $K_{s}$ determined from DANS and $K_{s}$ from water balance soil water deficit (Eqs. 6 and 7)

285 for the data from 2010 and 2011 LIRF corn. The fully irrigated corn was assumed to be non-

286 stressed. Similarly, the stress coefficient from DACT $\left(K_{s}\right)$ is calibrated by:

$$
K_{s}=\max \left(1-\frac{\mathrm{DACT}}{y}, 0\right)
$$

287 where $y$ is a variable optimized to reduce RMSE between $K_{s}$ determined from DANS and $K_{s}$

288 from water balance soil water deficit, also using 2010 and 2011 corn data. These equations were

289 designed to reach practical limits for $K_{s}$; that is, when DANS and DACT are zero, there is no

290 stress and $K_{s}$ is thus equal to 1 similar to Eq. 7. However, DANS $=x$ or DACT $=y$, would

291 indicate maximum stress therefore $K_{s}=0$. This study will focus on the performance of each

292 index under different irrigation treatments.

\section{$293 \quad$ 2.5. Stress coefficient $K_{s}$}

294 New values of $K_{s}$ obtained by stress detection methods CWSI, DANS, DACT, and $T_{\mathrm{c} \text { ratio }}$ 295 were all used in the place of the soil water deficit based $K_{s,}$ in order to evaluate the potential for 296 replacing soil water data with alternative inputs of canopy temperature and reflectance data.

297 DANS and DACT methods were applied according to Eq. (10) and Eq. (11) respectively, for 298 each treatment replication using temperature data collected at $1400 \mathrm{~h}$ and then those $K_{s}$ values 299 were averaged in order to find a daily value of $K_{s}$ for each method. 
$\mathrm{T}_{\text {cratio }}$ method was similarly applied using Eq. (9) with temperatures collected at $1400 \mathrm{~h}$.

$301 \mathrm{~T}_{\text {cratio }}$ does not fully conform to the definition of an index $[0,1]$ since the method cannot produce

302 a value of 0 even in the case of a non-transpiring crop. Despite this range issue, they are both

303 presented as potential surrogates of the FAO-56 water stress $K_{s}$ and were therefore be directly

304 evaluated as such (Bausch et al., 2011; DeJonge et al., 2016).

\section{$305 \quad$ 2.6. Method comparison}

Stress detection methods used to estimate stress coefficients $\left(K_{s}\right)$ are summarized in the

307 following list. For the sake of this comparison each was converted into an index before it was

308 used to calculate ET. In order to isolate and analyze the effect a particular $K_{c b}$ method may have

309 on the accuracy of each $K_{s}$ method, each stress coefficients were applied with each of tabular,

310 canopy cover, and NDVI based $K_{c b}$ values. $E T_{a}$ using all combinations of the four $K_{s}$ methods

311 and three $K_{c b}$ methods were compared to $E T_{a}$ from the data-assimilated water balance, as

312 described earlier. All four $K_{s}$ methods were obtained from stationary IRTs, with daily values

313 coming from 1400h, approximate time of peak stress:

314 1) CWSI as calculated with the empirical baseline (Eqn. 8, Idso et al.,1981)

315 2) Ratio of non-stress $T_{c}\left(T_{c N S}\right)$ to stress $T_{c}$ (Eqn. 11, Bausch et al., 2011)

316 3) DANS method (Eqn. 12, Taghvaeian et al., 2014a), normalized to yield values from 0 to 1

4) DACT method (Eqn. 13, DeJonge et al., 2015), normalized to yield values from 0 to 1

Once all stress coefficients had been calculated for the study period in 2012 and 2013,

320 each was evaluated compared to the observed neutron probe and soil water balance ET

321 measurements. The main statistics to evaluate the performance of each method are the root mean

322 square error (RMSE) mean biased error (MBE), shown respectively as: 


$$
\begin{gathered}
\left.\mathrm{RMSE}=\left[N^{-1} \sum_{i=1}^{N}\left(P_{i^{-}} O_{i}\right)\right]^{2}\right]^{0.5} \\
\mathrm{MBE}=N^{-1} \sum_{i=1}^{N}\left(P_{i^{-}} O_{i}\right)
\end{gathered}
$$

323 where $N$ is the number of observations, $P$ is the model-prediction, and $O$ is an observation.

324 RMSE summarizes model error in terms of magnitude and MBE describes model bias.

\section{3. Results and Discussion}

\section{3.1. Example dataset}

Because this study uses a combination of nine unique treatments over a course of four years (Table 1), it is infeasible to comprehensive datasets of daily soil water content or deficit, canopy temperature, and other seasonal measurements such as yield or ET. However, to help the readers of this manuscript gain an understanding of the soil water deficits and canopy

331 temperatures observed, a subset of Treatments 1, 8, and 12 from the year 2013 are used as an

332 illustratory example. These three treatments have increasing levels water stress, receiving a goal 333 of $100 \%, 65 \%$, and $40 \%$ of full ET, respectively, during vegetative and maturity growth stages

334 (Table 1). Soil water deficit ( $\mathrm{D}_{\mathrm{r}}$, Eq. 7) and readily available water in the root zone are shown in 335 Figure 1A, daily canopy temperature $\left(T_{c}\right)$ at 1400h is shown in Figure 1B, and crop yield at $33615.5 \%$ moisture and cumulative seasonal $\mathrm{ET}_{\mathrm{c}}$ are shown in Figures $1 \mathrm{C}$ and $1 \mathrm{D}$, respectively. In Figure 1A, the red line (RAW) represents the readily available water in the root zone,

338 which grows throughout the season due to root growth. Simply put, if $\mathrm{D}_{\mathrm{r}}$ is above the RAW line, 339 the crop will experience water stress (Eq. 7). In the time series figures for $\mathrm{D}_{\mathrm{r}}$ and $T_{c}$, the sensitive 340 reproductive growth stage where the crop is taken out of water stress is shown in grey. At this 
341 time, soil water deficit for all treatments is reduced to near 0 following irrigation events (Figure

$3421 \mathrm{~A}$ ), and consequently canopy temperature $T_{c}$ is also reduced (Figure 1B). In this example,

343 vegetative stress was achieved in Trts 12 and 8, however late season rainfall (which caused

344 significant flooding in northern Colorado) made it difficult to achieve desired levels of stress in

345 Trt 8 in the reproductive growth stages.

346 As with soil water deficit, canopy temperature $T_{c}$ had increasing values throughout the

347 season between Trts 1, 8, and 12 respectively. Early season temperatures were higher than mid-

348 season, likely because at this time the crops had not achieved full canopy cover and the sensors

349 were viewing soil background (crops not under full cover were screened from later analysis).

350 Throughout most of the season, Trt 1 typically remained at or below $28{ }^{\circ} \mathrm{C}$, the threshold at

351 which DANS indicates stress. Even under full irrigation, under high evaporative demand and

352 ambient temperature crops will sometimes spike to higher canopy temperatures, which may be

353 due to heat stress rather than water stress. Further research is needed to categorize the often

354 confused distinction between water stress and heat stress, and to quantify to what extent heat

355 stress alone can reduce $E T_{c}$.

356 Treatments 1, 8 and 12 yielded 15699,13903 , and $8567 \mathrm{~kg} \mathrm{ha}^{-1}$; and had seasonal $E T_{c}$ of

357627,542 , and $450 \mathrm{~mm}$, respectively (Fig 1C and 1D). These numbers are typical of the treatment

358 differences found in our experiment. It is likely that $\operatorname{Trt} 8$ did not see as much of a drop in yield

359 in 2013 due to the large rainfall events during the maturity growth stages (following

360 reproductive), which took it largely out of stress (e.g. canopy temperatures in late season were

361 very close to $\operatorname{Trt} 1)$.

$362 \quad$ 3.1. DANS and DACT calibration 
DANS and DACT are both in units of ${ }^{\circ} \mathrm{C}$, so in order to use them as unitless stress

364 coefficients a method to normalize them was required. In order to calibrate parameters $x$ and $y$ in 365 Eq. (12) and (13), FAO-56 soil water-based $K_{s}$ values were calculated from a neutron probe 366 calibrated soil water balance from corn at LIRF in 2010 and 2011 . These $K_{s}$ numbers were then 367 used to identify the values for $x$ and $y$ which minimized the RMSE of DANS and DACT $K_{s}$ 368 values for 2010 and 2011. Considering all treatments and both years, optimized values for $x$ and $369 y$ used in this study were 29.1 and $27.7^{\circ} \mathrm{C}$, respectively. The optimized values for both DANS 370 and DACT were similar because the non-stress crop was often near $28^{\circ} \mathrm{C}$. Average $1400 \mathrm{~h}$ 371 temperature of the non-stress canopy was 27.6 for 2010 and 27.9 in 2011, and for the stressed

372 crops (all but Treatment 1) at same time of day, average canopy temperature was 29.3 for 2010

373 and 31.0 for 2011 . Measured temperatures of near $28^{\circ} \mathrm{C}$ for the non-stress crop supports the use 374 of $28^{\circ} \mathrm{C}$ as the threshold for stress in DACT index to represent the temperature that a well375 watered crop will maintain under conditions when the canopy of a water-stressed crop will be 376 higher. Calibrations from 2010 and 2011 data yielded very similar RMSE and MBE values for 377 both DANS and DACT stress coefficients, comparing similar treatments (Figures 2 and 3). Low 378 RMSE and MBE values indicate that DANS and DACT are closely related to a water stress 379 index and have the potential to be use to calculate stress coefficients.

380 Figures 2 and 3 illustrate how the error in $K_{s}$ calculated from DANS and DACT change 381 for different experimental years and treatment combinations, with varying values of calibration 382 coefficients $x$ and $y$. These graphs show that for parameter values above 15, the overall error is 383 nearly constant with asymptotic behavior around a minimum RMSE of approximately 0.15 when 384 considering all treatments. This indicates the indices may not be overly sensitive to these 385 coefficients but stress level can still help predict what best value of $x$ or $y$ will be. A non-stress 
crop will have lowest error with an infinitely large value for $x$ or $y$ in order to force all $K_{s}$ values

387 to 1 , while a severely-stressed crop such as Treatment 5 in this study appears to have highest

388 accuracy when using a variable of $x$ or $y$ within a range of roughly 16 to 19 . A moderately

389 stressed crop, represented by Treatment 4, may be best described by a parameter between 20 and

39030 for either DANS (or DACT) indices. Eliminating non-stress plots from this analysis resulted

391 in optimized $x$ values of 23.2 in 2010 and 20.1 in 2011, and $y$ values of 26.6 in 2010 and 24.4 in

392 2011, which may indicate that the range of 20 to 30 is an optimal range for either index if the

393 exact stress level is unknown, as optimized values fall within this range for all deficit treatments

394 in this study. On the other hand, if calibrating specifically for application with very stressed

395 crops, lower values of $x$ and $y$ (i.e. 15 to 20) may be ideal. Further research is necessary to fine

396 tune the relationship between optimal empirical values and stress level in order to establish

397 confidence in choosing these parameters without data from previous years and determine the

398 sensitivity and transferability under different climactic conditions, crops, and/or hybrids. The

399 sensitivity to stress level may also indicate that the normalization equations or methodology may

400 need to be adjusted, either by applying more severe stress functions, and/or focusing solely on

401 stressed treatments for calibration.

402 3.2. Evaluation of $\boldsymbol{E} \boldsymbol{T}_{c}$ estimates

403 All $K_{s}$ methods were evaluated within a soil water balance spreadsheet which uses FAO-

40456 dual crop coefficient method to estimate actual evapotranspiration. Daily $E T_{c}$ estimations for

405 all combinations of $K_{s}$ and $K_{c b}$ were compared to daily $E T_{c}$ values from observed soil water

406 content and calculated soil water balance. $E T_{c}$ RMSE (mm/day) estimates from each

407 combination of $K_{s}$ and $K_{c b}$ method over the study period in 2012 and 2013 are shown in Table 3.

408 For all $K_{s}$ methods in 2013, the effect of using canopy cover measurements instead of tabular 
409 values resulted in only slightly reduced error (an average of $0.04 \mathrm{~mm} /$ day) and using NDVI to

410 calculate canopy cover also only slightly improved accuracy over using tabulated values (an

411 average of $0.05 \mathrm{~mm} /$ day, Table 3). The five $K_{s}$ methods performed at similar levels of accuracy,

412 and the low RMSE of DANS and DACT as compared with CWSI indicates that these indices

413 have potential to be used as stress coefficients. Tabulated $K_{c b}$ values resulted in more error over

414 canopy cover $K_{c b}$ values in 2012, increasing RMSE an average of $0.17 \mathrm{~mm} /$ day compared to the

$4150.04 \mathrm{~mm} /$ day seen in 2013. In 2012 CWSI performed slightly worse than the other methods with

416 an average RMSE of $0.96 \mathrm{~mm}$ /day compared to the average RMSE of all other methods which

417 was $0.84 \mathrm{~mm} /$ day.

418 Each method's predicted $E T_{c}$ was compared with FAO-56 derived $E T_{c}$, as shown by

419 scatterplots (Figure 4) which include bias measurement via best fit line (assuming intercept of 0 )

420 and coefficient of determination $\mathrm{R}^{2}$ for each method. CWSI $E T_{c}$ showed the least bias with slope

421 of 0.989 , while DACT and $T_{\text {cratio }} E T_{c}$ had slope of 0.953 and DANS with 0.949. CWSI $E T_{c}$ and

422 DANS $E T_{c}$ had the highest $\mathrm{R}^{2}$ values of the methods with 0.86 and 0.85 , respectively. Both

423 CWSI and DANS had high scatter for lower $E T_{c}$ values, with DANS more consistently

424 overestimating on days with less $E T_{c}$. DANS, while having an overall slightly lower $\mathrm{R}^{2}$ than

425 CWSI has less scatter among the mid-range $E T_{c}$ values which demonstrates that DANS performs

426 very well for days with average $E T_{c}$, while CWSI had quite a bit of scatter throughout the whole

427 range of $E T_{c}$ values. High error among all methods on days with lower $E T_{c}$ can also be attributed

428 to these days being those with lower reference $E T_{c}$ and therefore having lower stress, which is

429 what these methods are designed to detect. DACT and $T_{\text {cratio }}$ both had $\mathrm{R}^{2}$ values of 0.83 ,

430 respectively. 
Figure 5 displays the RMSE (mm/day) of daily $E T_{c}$ estimates for each stress coefficient

432 method separated by treatment in order to see the effect of irrigation level on the performance of

433 each method. This figure shows that the performance of each stress coefficient was similar for all

434 treatment levels, with higher stress treatments incurring higher errors from all methods. Figure 6

435 displays the MBE of daily $E T_{c}$ estimates over the study period and this chart shows that all of the

$436 K_{s}$ methods slightly over-estimated $E T_{c}$ with canopy cover-based $K_{c b}$ values and slightly

437 underestimate $E T_{c}$ when applied with NDVI and tabular $K_{c b}$ values. In addition this figure

438 indicates that a composite $K_{c b}$ model, averaging the three methods, could be the least biased

439 estimate for $K_{c b}$, although both NDVI and fc can always be biased by methodology and sensors

440 used

441 In order to evaluate the performance of each $K_{s}$ method by cumulative water use

442 estimations, average values from the three $K_{c b}$ methods (tabular, $f_{c}$, NDVI) were used eliminate

443 its effect on the outcome. Cumulative seasonal error in estimations of total $E T_{c}(\mathrm{~mm})$ over 2013

444 for each $K_{s}$ method is shown graphically in Figure 7. All $K_{s}$ methods consistently underestimated

$445 E T_{c}$ for less stressed treatments $1-3$, and often overestimated $E T_{c}$ for the more stressed

446 treatments. DANS had less error than CWSI for the deficit treatments, which shows that the

447 DANS method has promise under water stress conditions. However, one must consider that the

448 CWSI method was applied in this study with relative humidity and air temperature data obtained

449 from the nearest weather station. This is, not with in-situ data as the method prescribes. If in-situ

450 relative humidity and air temperature were available, most probably more accurate values of

451 CWSI could have been obtained, which would lead to more appropriate irrigation scheduling

452 (Taghvaeian et al., 2014b). Similarly, the average seasonal performance of DACT with only -

$4530.5 \%$ error in total $E T_{c}$ estimation compared to $1.0 \%$ error of CWSI shows that if there is no 
454 onsite air temperature and relative humidity data, DACT has the potential to perform as well as

455 CWSI for prediction of stress and estimation of $E T_{c}$ with only the single input of a canopy

456 temperature measurement.

\section{3.3. Practical considerations}

This study has practical ramifications for consultants, producers, and researchers

459 choosing between different water stress and irrigation water management techniques. Data

460 availability governs the available options discussed in this paper. Table 4 summarizes the data

461 requirements for each method and presents the RMSE of daily $E T_{c}$ for each in order to analyze if

462 increased data requirement corresponds to increased accuracy. In Table 4, "target" refers to the

463 crop in question for which a $K_{s}$ value is being assigned.

464 DANS and DACT have fewer data requirements, yet only a decrease in accuracy of 0.03

$465 \mathrm{~mm} /$ day $(0.6 \%)$ in $E T_{c}$ estimation compared to CWSI. This comparability of DACT to CWSI is

466 particularly noteworthy because the DACT method only requires a single canopy temperature

467 measurement. DACT also may be applicable in more situations than DANS or $T_{\text {cratio }}$ because, in

468 times of drought, a comparable non-stress canopy may not exist, or there could be stresses other

469 than water stress contributing to higher canopy temperatures (i.e. disease, high air temperatures,

470 etc.). However, it is worth noting that the DACT and DANS methods have been locally

471 calibrated (trained) and therefore a good performance was expected while the other methods

472 have been applied as they have been published in the literature (i.e., without local calibration and

473 in the case of the CWSI index without in situ weather data). The analyses in previous figures and

474 tables provide guidelines for a variety of different irrigation levels and data availability.

475 Although canopy temperature data was acquired on a continuous basis, only data from

476 1400h was used in the creation of the indices and subsequent analysis. This time was chosen 
477 based on numerous other studies which choose evaluation times near solar noon, or when peak

478 stress often occurs. If farmers were to use these techniques for irrigation scheduling, they may be

479 more likely to obtain a "snapshot" within a specific timeframe of the day (either from an

480 integrating sensor, or possibly a spatial thermal infrared image) than to have continuous

481 stationary sensors (DeJonge et al., 2015). Further work is suggested to specifically define and

482 categorize the optimal timeframe for canopy temperature evaluation, which may lend itself to

483 even better accuracy.

484 For methods like DANS and $\mathrm{T}_{\text {cratio, }}$, the use of a non-stressed crop to determine $\mathrm{T}_{\mathrm{cNS}}$ can

485 be somewhat problematic, as it has the additional requirement of maintaining a fully irrigated,

486 non-stressed crop. This additional step may have practical limitations in regard to additional

487 requirements for producers. It is conceivable that this information, through manipulation of the

488 Penman-Monteith reference ET equation, could be indirectly found by nearby reference ET

489 weather stations such as those provided by CoAgMet. DANS and $\mathrm{T}_{\text {cratio }}$ also have numerical

490 limitations, requiring either choosing the lowest observed $T_{c}$ as $T_{c N S}$, or by setting a numerical

491 limit for the value (e.g. DANS $\geq 0, \mathrm{~T}_{\text {cratio }} \leq 1$ ). Limitations of these methods are discussed in

492 more detail in DeJonge et al. (2015).

493

494 4. Conclusion

This study compared and evaluated the accuracy of several water stress coefficient

496 methods for estimating crop $E T_{c}$ under different levels of deficit irrigation. Results can inform

497 users which stress coefficient will most likely perform best given the available data and irrigation

498 level in addition to providing an estimation of the expected error in $E T_{c}$ estimations. Using the

499 most appropriate water stress coefficient method has the potential to improve irrigation 
500 scheduling to more precisely manage stress and therefore allow crops to reach the maximum

501 possible yield given a limited irrigation water supply. Results also give researchers indications of

502 which methods have the most potential to be further investigated and refined. Methods using

503 only canopy temperature measurements (DANS, DACT, and $T_{\text {cratio }}$ ) performed with comparable

504 error to more data intensive methods such as CWSI and demonstrated the potential for simple

505 methods to be used for irrigation scheduling.

$506 \quad$ Future studies should evaluate how stress coefficient methods perform in various

507 climates, for different crops, and under different irrigation methods. This study focused on drip

508 irrigated corn in Northern Colorado over 2 years. Future work is needed to investigate the

509 transferability of DANS and DACT as stress coefficients and the sensitivity of the empirical

510 component. A wider range of environmental conditions would be required to test the

511 performance of these methods for various climatological conditions. Use of a large monolithic

512 weighing lysimeters to validate daily $E T_{c}$ values increase confidence in the results. This study

513 was conducted with research grade IRTs, but future work should test the sensitivity of each

514 temperature-based $\mathrm{K}_{\mathrm{s}}$ method to errors in crop canopy temperature in order to study feasibility of

515 using less expensive IRTs to monitor crop water stress. Another study could apply each method

516 using remotely sensed reflectance and temperature from aerial platforms and compare the

517 performance of various stress coefficient methods when applied on different levels. Results from

518 comparing various platforms of remote sensing to calculate stress coefficients could provide

519 irrigation districts with recommendations how to inexpensively use remote sensing on a larger

520 scale to estimate crop water use and improve water management under deficit irrigation. 


\section{ACKNOWLEDGEMENTS}

Funding for this study was provided by the USDA-NRCS Conservation Innovation

525 Grant, USDA-ARS Water Management Unit, Colorado Water Conservation Board, Northern

526 Colorado Water Conservancy District, West Greeley Conservancy District and Central Colorado

527 Water Conservancy District. The authors thank Drs. Tom Trout and Saleh Taghvaeian, whose

528 reviews on an earlier draft significantly strengthened the paper.

529

530

\section{REFERENCES}

Alderfasi, A.A., Nielsen, D.C., 2001. Use of crop water stress index for monitoring water

532 status and scheduling irrigation in wheat. Agric. Water Manage. 47(1), 69-75.

Allen, R.G., Pereira, L.S., Raes, D., Smith, M., 1998. Crop evapotranspiration-Guidelines

534 for computing crop water requirements-FAO Irrigation and drainage paper 56. FAO, Rome, 300, 5356541.

Allen, R.G., Wright, J.L., Pruitt, W.O., Pereira, L.S., Jensen, M.E., 2007. Water

537 requirements, in Hoffman, G.J., Evans, R.G., Jensen, M.E., Martin, D.L., Elliott, R.L. (Eds.),

538 Design and Operation of Farm Irrigation Systems. 2nd ed. American Society of Agricultural and

539 Biological Engineers.

ASCE, 2005. The ASCE Standardized Reference Evapotranspiration Equation. ASCE-

541 EWRI, Reston, VA.

542 Burke, J.J., 1996. Personal communication to S.R. Evett from the USDA-ARS Crop

543 Stress Research Laboratory, Lubbock, Texas. 
Bausch, W.C., 1993. Soil background effects on reflectance-based crop coefficients for

545 corn. Remote Sens. Environ. 46(2), 213-222.

546 Bausch, W., Trout, T., Buchleiter, G., 2011. Evapotranspiration adjustments for

547 deficit-irrigated corn using canopy temperature: A concept. Irrig. Drain. 60(5), 682-693.

548 Clawson, K.L., Blad, B.L., 1982. Infrared thermometry for scheduling irrigation of

549 corn. Agron. J. 74(2), 311-316.

550 Conaty, W., 2010. Temperature time thresholds for irrigation scheduling in precision

551 application and deficit furrow irrigated cotton. Doctoral dissertation, Faculty of Agriculture Food

552 and Natural Resources, The University of Sydney, NSW, Australia.

553 DeJonge, K.C., Andales, A.A., Ascough II, J.C., Hansen, N.C., 2011. Modeling of full

554 and limited irrigation scenarios for corn in a semiarid environment. Trans. ASABE 54(2): 481-

555492.

556 DeJonge, K.C., Taghvaeian, S., Trout, T.J., Comas, L.H., 2015. Comparison of canopy

557 temperature-based water stress indices for maize. Agric. Water Manage. 156, 51-62.

558 DeJonge, K.C., Mefford, B.S, Chávez, J.L. 2016. Assessing corn water stress using

559 spectral reflectance. Int. J. Remote Sens. 37(10): 2294-2312.

560 Evett, S.R., Tolk, J.A., Howell, T.A., 2006. Soil profile water content determination:

561 sensor accuracy, axial response, calibration, temperature dependence, and precision. Vadose

562 Zone J. 5(3), 894-907.

563 Fereres, E., Soriano, M.A., 2007. Deficit irrigation for reducing agricultural water use. J.

564 Exp. Bot. 58(2), 147-159.

565 Huisman, J.A., Hubbard, S.S., Redman, J.D., Annan, A.P., 2003. Measuring soil water

566 content with ground penetrating radar. Vadoze Zone J. 2(4), 476-491. 
568 Normalizing the stress-degree-day parameter for envioronmental variability. Agric. Meteorol. $56924(1), 45-55$.

570 Idso, S.B., 1982. Non-water-stressed baselines: a key to measuring and interpreting plant 571 water stress. Agric. Meteorol. 27, 59-70. water stress indicator. Water Resour. Res. 17(4), 1133-1138.

Johnson, L.F., Trout, T.J., 2012. Satellite NDVI assisted monitoring of vegetable crop evapotranspiration in California's San Joaquin Valley. Remote Sens. 4(2), 439-455.

Kang, S., Shi, W., Zhang, J., 2000. An improved water-use efficiency of maize grown

577 under regulated deficit irrigation. Field Crops Res. 67: 207-214. ground-based thermal remote sensing in agriculture: a review. J. Exp. Bot. 63(13), 4671-4712. irrigation on accumulation of canopy temperature-based heat units in cotton. J. Cotton Sci. 18: $582 \quad 129-136$.

584 through an irrigation scheduling service. Irrig. Sci. 29(4), 311-319. 
Taghvaeian, S., Chávez, J.L., Hansen, N.C., 2012. Infrared thermometry to estimate crop

590 water stress index and water use of irrigated maize in Northeastern Colorado. Remote

591 Sens. 4(11), 3619-3637.

592 Taghvaeian, S., Comas, L., DeJonge, K.C., Trout, T. J., 2014a. Conventional and

593 simplified canopy temperature indices predict water stress in sunflower. Agric. Water

594 Manage. 144, 69-80.

595 Taghvaeian, S., Chávez, J.L., Bausch, W.C., DeJonge, K.C., Trout, T.J., 2014 b.

596 Minimizing instrumentation requirement for estimating crop water stress index and transpiration

597 of maize. Irrig. Sci. 32(1), 53-65.

598 Topp, G.C., Ferré, P.A., 2002. Water content, in Dane, J.H., Topp, G.C. (Eds.), Methods

599 of Soil Analysis: Part 4, Physical Methods. Soil Sci. Soc. Am. Book Ser., v5, 417-446. Soil Sci.

600 Soc. Of Am., Madison, Wis.

601 Trout, T.J, Johnson, L.F., 2007. Estimating crop water use from remotely sensed NDVI,

602 crop models, and reference ET, in Clemmens, A.J., Anderson, S.S. (Eds.), The Role of Irrigation

603 and Drainage in a Sustainable Future: Proceedings of the USCID Fourth International

604 Conference on Irrigation and Drainage, Sacramento, CA, 3-6 October 2007, pp: 275-285.

605 Trout, T.J., Johnson, L.F., Gartung, J., 2008. Remote sensing of canopy cover in

606 horticultural crops. HortScience 43(2), 333-337.

607 Trout, T.J., 2016. USDA-ARS Colorado maize water productivity dataset 2008-2011. Ag

608 Data Commons.

609 United Nations, 2012. The 2012 Revision of the World Population Prospects. United

610 Nations, New York. 
Walthall, C.L., Hatfield, J., Backlund, P., Lengnick, L., Marshall, E., Walsh, M., Adkins,

612 S., Aillery, M., Ainsworth, E.A., Ammann, C., Anderson, C.J., Bartomeus, I., Baumgard, L.H.,

613 Booker, F., Bradley, B., Blumenthal, D.M., Bunce, J., Burkey, K., Dabney, S.M., Delgado, J.A.,

614 Dukes, J., Funk, A., Garrett, K., Glenn, M., Grantz, D.A., Goodrich, D., Hu, S., Izaurralde, R.C.,

615 Jones, R.A.C., Kim, S-H., Leaky, A.D.B., Lewers, K., Mader, T.L., McClung, A., Morgan, J.,

616 Muth, D.J., Nearing, M., Oosterhuis, D.M., Ort, D., Parmesan, C., Pettigrew, W.T., Polley, W.,

617 Rader, R., Rice, C., Rivington, M., Rosskopf, E., Salas, W.A., Sollenberger, L.E., Srygley, R.,

618 Stöckle, C., Takle, E.S., Timlin, D., White, J.W., Winfree, R., Wright-Morton, L., Ziska, L.H.,

619 2012. Climate Change and Agriculture in the United States: Effects and Adaptation. USDA

620 Technical Bulletin 1935. Washington, DC.

621 Zia, S., Sophrer, K., Wenyong, D., Spreer, W., Romano, G., Xiongkui, H., Müller, J.,

622 2011. Monitoring physiological responses to water stress in two maize varieties by infrared

623 thermography. Int. J. Agric. Biol. Eng. 4(3), 7-15.

624 

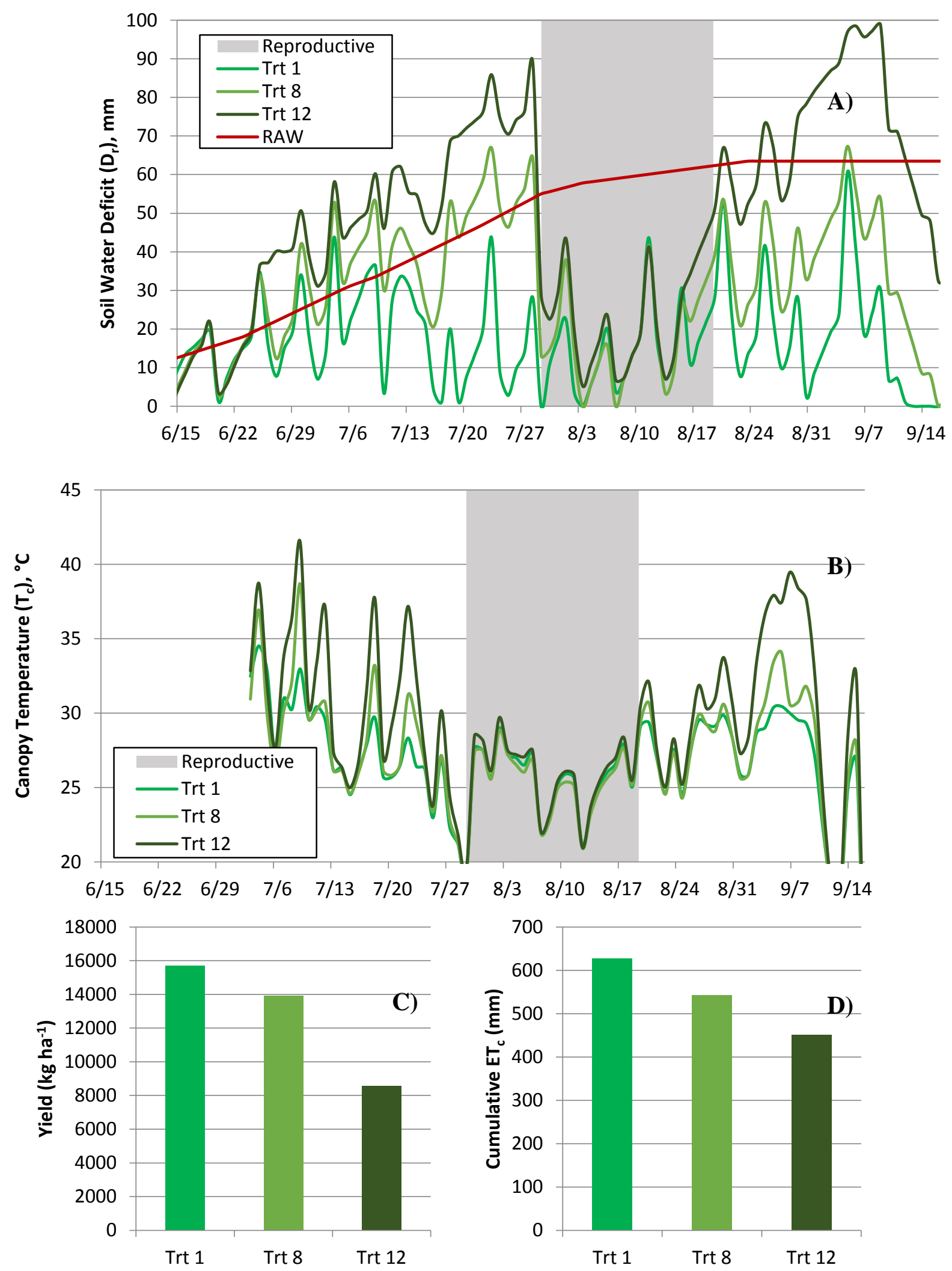
$629 \mathrm{ET}_{\mathrm{c}}(\mathrm{D})$ for Treatments 1,8 , and 12 in 2013. RAW in (A) designates readily available water

$630(\mathrm{~mm})$. Reproductive growth stage in grey indicates when crops were taken out of stress. 


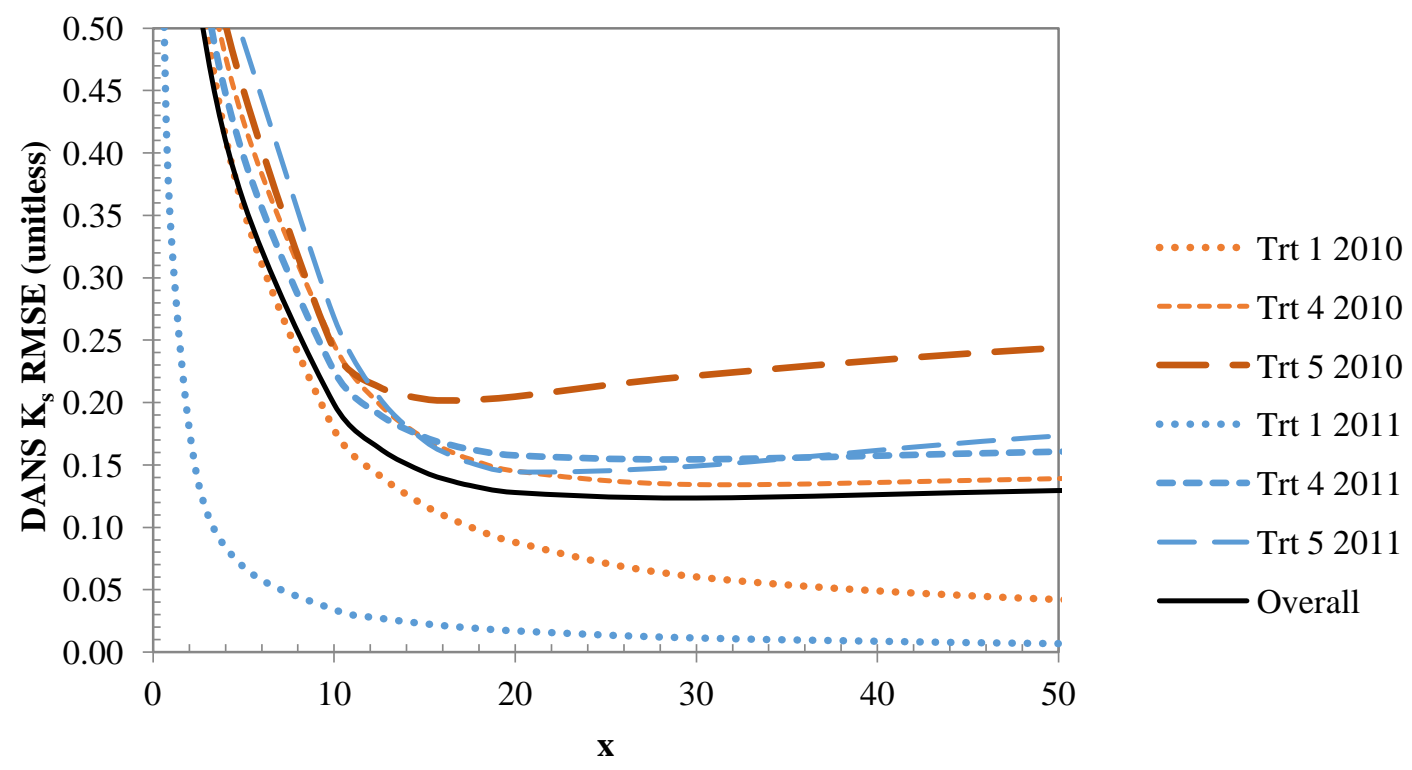

632

633 Figure 2. Optimization of transfer from DANS to crop stress coefficient $K_{s}$. DANS calibration 634 RMSE with varying $x$ values for each treatment and year combination. DANS $K_{s}=\max (1-$

$635 \mathrm{DANS} / x, 0)$; values were compared with $K_{s}$ found from soil water deficit. Optimized at $x=27.7$ $636 \quad(\mathrm{RMSE}=0.15, \mathrm{MBE}=0.033)$. 


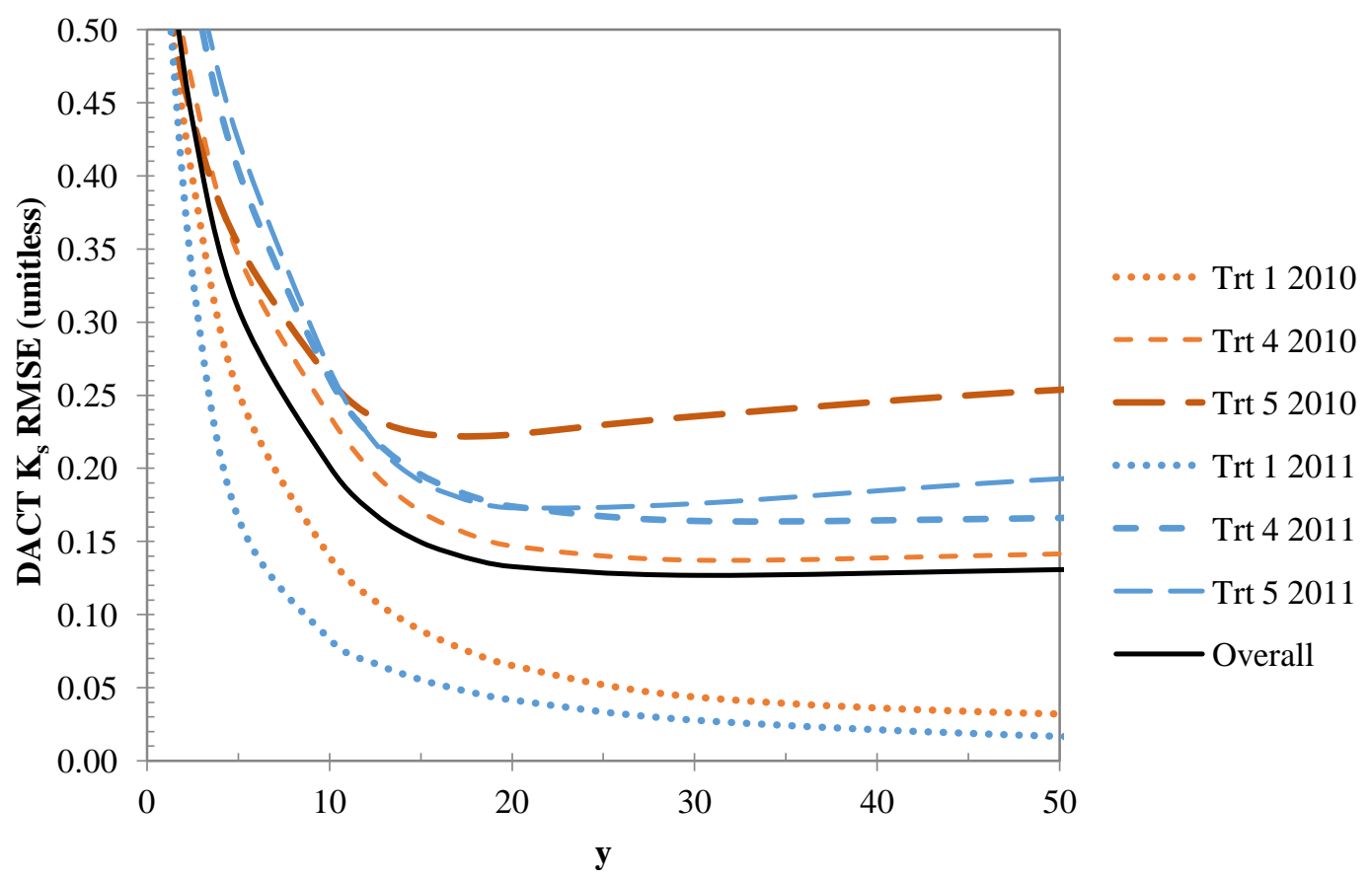

640

641 Figure 3. Optimization of transfer from DACT to crop stress coefficient $K_{s}$. DACT calibration 642 RMSE with varying $y$ values for each treatment and year combination. DACT $K_{s}=\max (1-$

$643 \mathrm{DANS} / y, 0)$; values were compared with $K_{s}$ found from soil water deficit. Optimized at $y=29.1$ $644 \quad(\mathrm{RMSE}=0.14, \mathrm{MBE}=-0.031)$. 

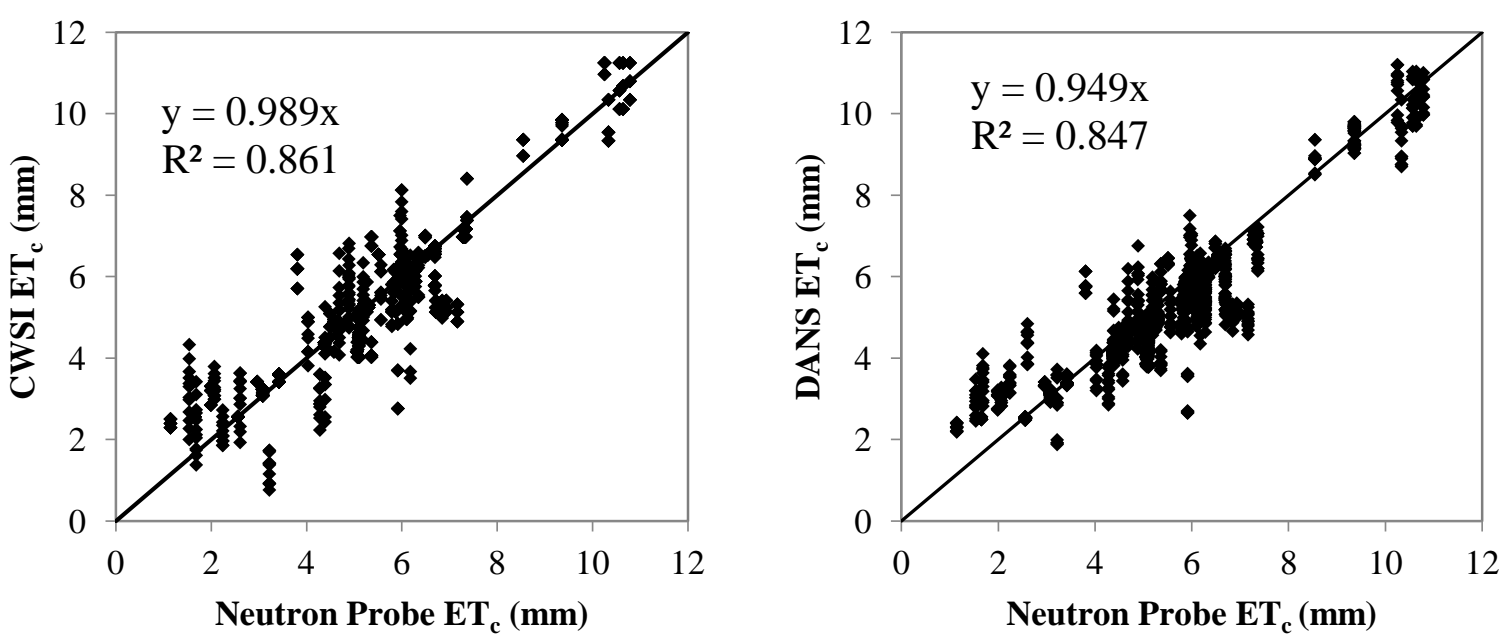

646
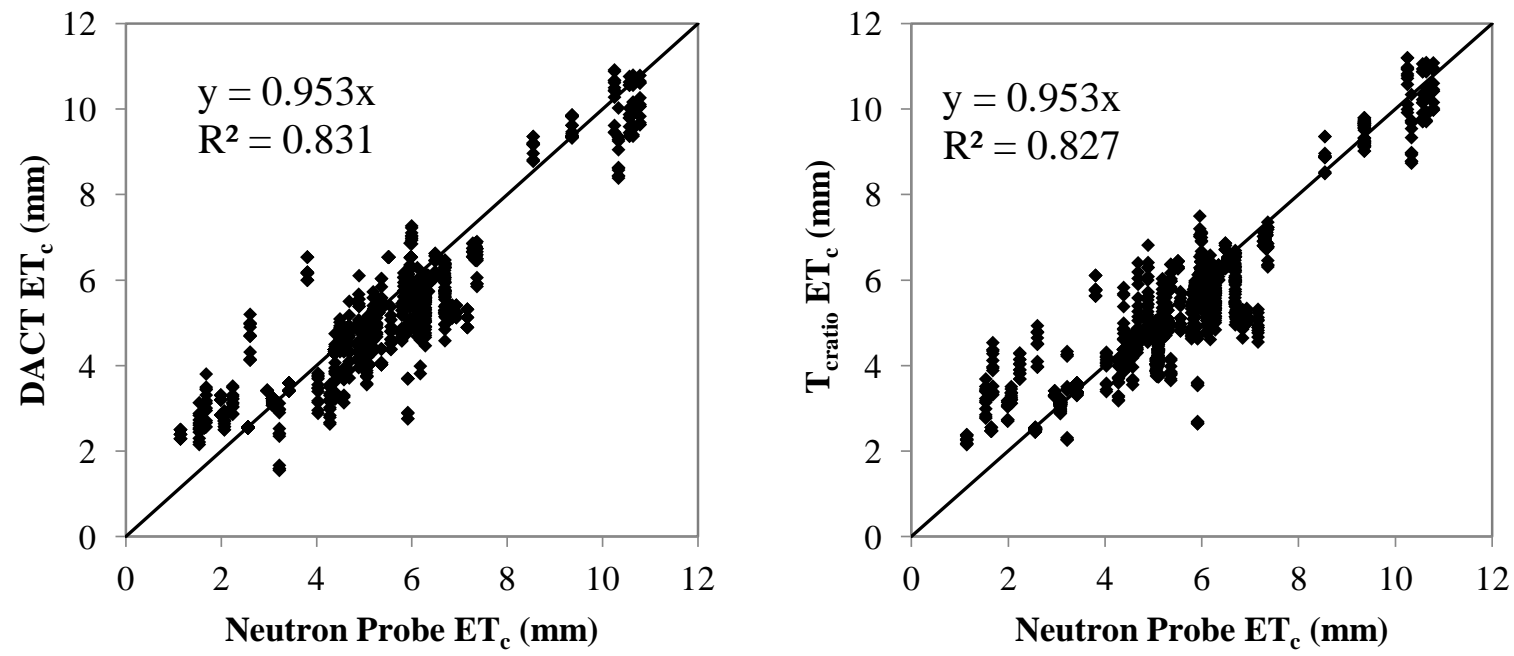

648 Figure 4. Scatterplots of $E T_{c}$ obtained using various stress coefficient methods vs. $E T_{c}$ obtained 649 by neutron probe soil water balance. Methods include CWSI, DANS, DACT, and $\mathrm{T}_{\text {cratio. }}$ 


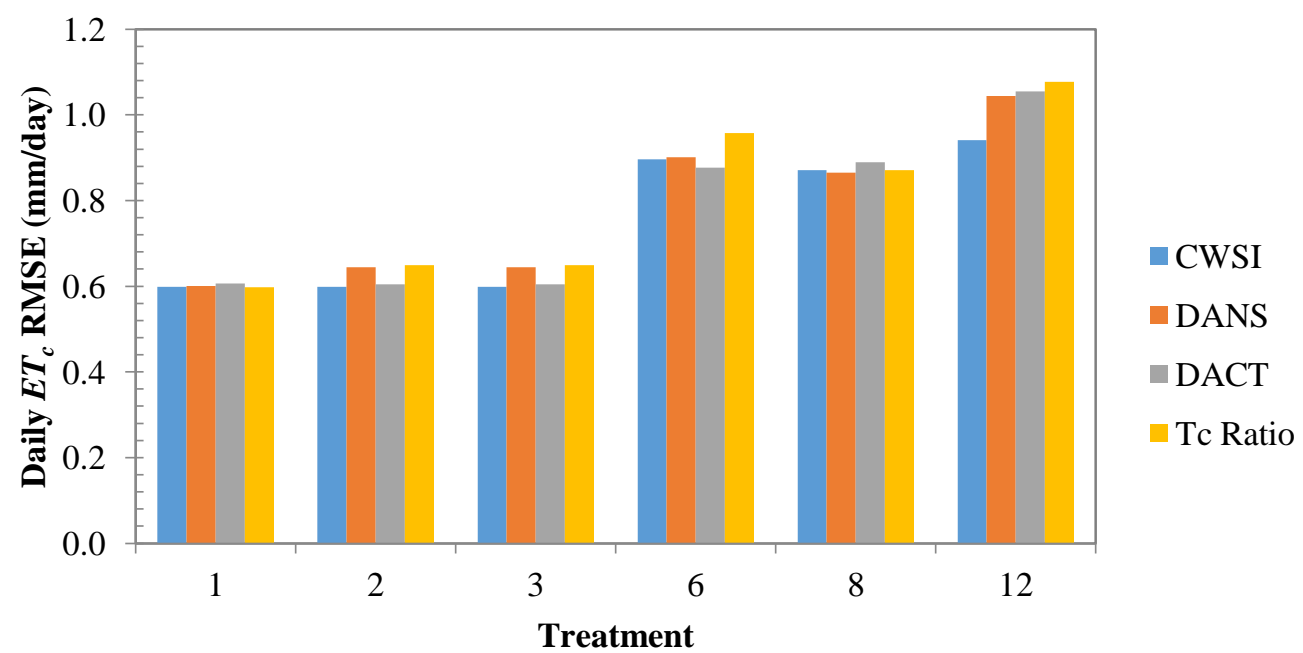

652

653 Figure 5. Daily $E T_{c}$ estimate RMSE (mm/day) of each $K_{s}$ method for each treatment, as 654 compared to $E T_{c}$ from neutron probe soil water balance.

655

656 

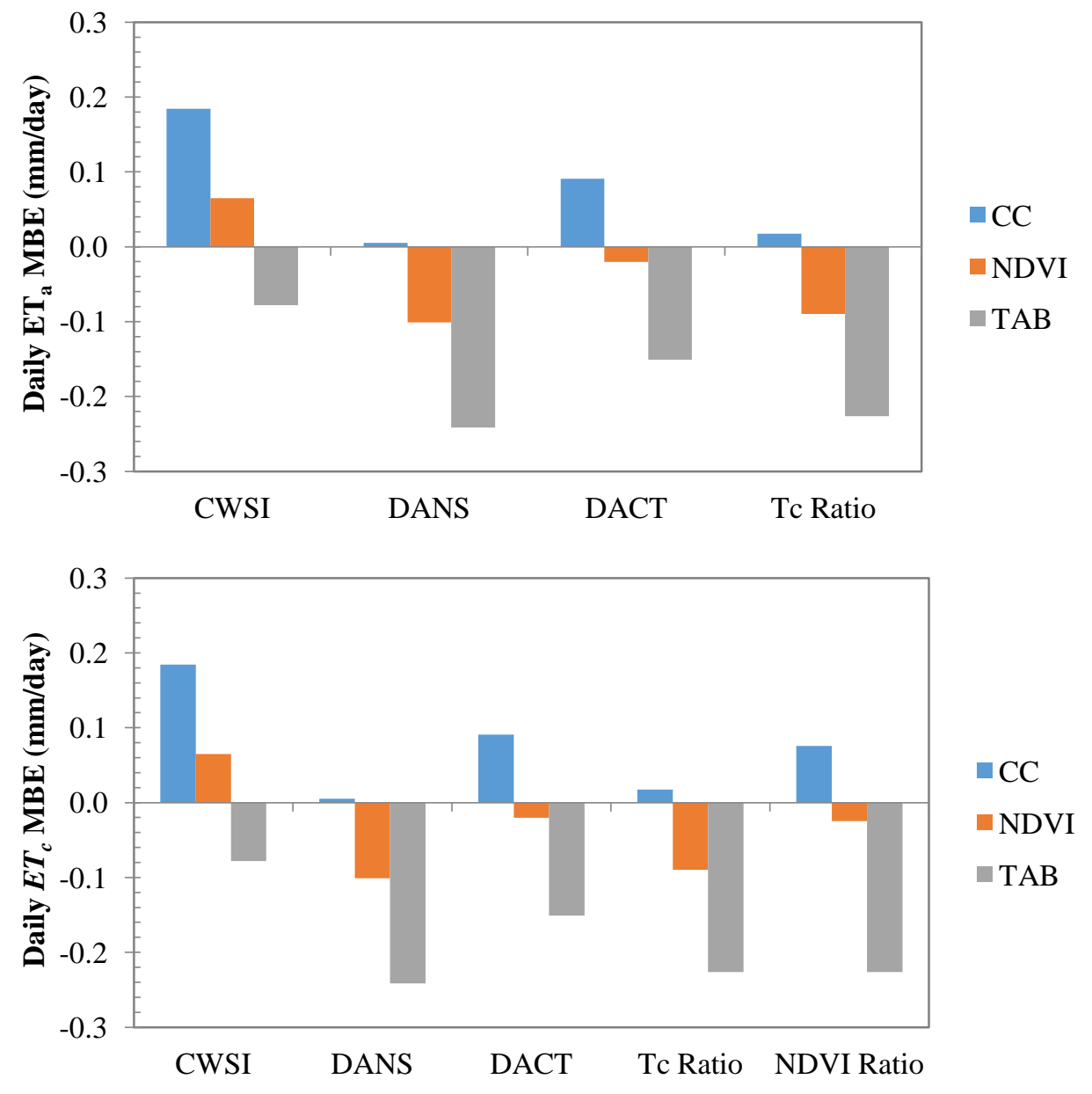

660 Figure 6. Daily $E T_{c}$ estimate MBE (mm/day) of each combination of $K_{s}$ and $K_{c b}$ methods, as 661 compared to $E T_{c}$ from neutron probe soil water balance. $K_{c b}$ methods used are canopy cover 662 (CC), normalized difference vegetation index (NDVI), and tabular values (TAB).

663

664

665 


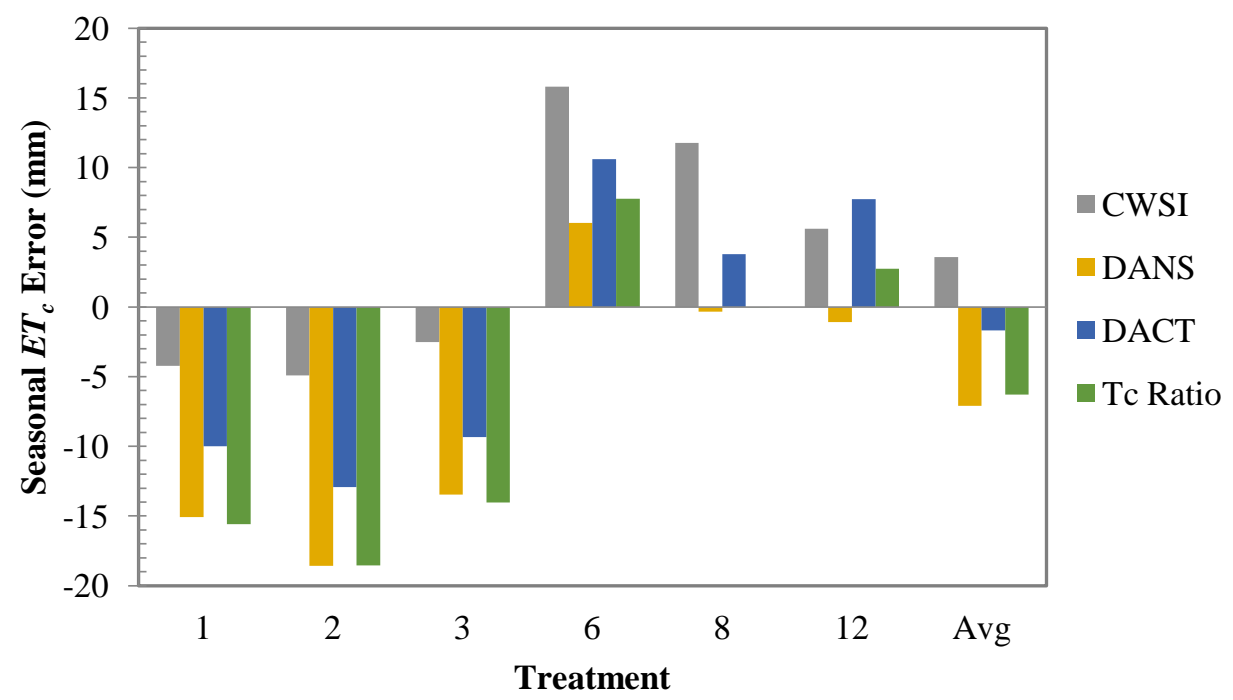

666

667 Figure 7. Cumulative $E T_{c}(\mathrm{~mm})$ error of each $K_{s}$ method for each treatment over the 2013 season. 668

669 
670 Table 1. Irrigation treatments used in study. All treatments had four replicates unless indicated 671 otherwise.

\begin{tabular}{ccccc}
\hline Years & Treatment \# & $\begin{array}{c}\text { Vegetative } \\
\text { \% ET }\end{array}$ & $\begin{array}{c}\text { Reproductive } \\
\text { \% ET }\end{array}$ & $\begin{array}{c}\text { Maturity } \\
\text { \% ET }\end{array}$ \\
\hline \multirow{2}{*}{2010,2011} & 1 & 100 & 100 & 100 \\
& 4 & 70 & 70 & 70 \\
& 5 & 55 & 55 & 55 \\
\hline \multirow{2}{*}{2012,2013} & 1 & 100 & 100 & 100 \\
& 2 & 100 & 100 & 50 \\
& 3 & 80 & 100 & 80 \\
& 6 & 80 & 100 & 40 \\
& $8^{\mathrm{a}}$ & 65 & 100 & 65 \\
& $10^{\mathrm{b}}$ & 65 & 100 & 40 \\
& 12 & 40 & 100 & 40 \\
\hline
\end{tabular}

${ }^{\mathrm{a}}$ Three replicates in 2012

${ }^{\mathrm{b}}$ No $T_{c}$ observations in 2012 
674 Table 2. Average daily weather parameters during study period (7 July - 7 Sept.) for $2010-$ 6752013

\begin{tabular}{lrrrr}
\hline Parameter & $\mathbf{2 0 1 0}$ & $\mathbf{2 0 1 1}$ & $\mathbf{2 0 1 2}$ & $\mathbf{2 0 1 3}$ \\
\hline Mean air temp. $\left({ }^{\circ} \mathrm{C}\right)$ & 21.2 & 22.3 & 22.1 & 21.6 \\
Max air temp. $\left({ }^{\circ} \mathrm{C}\right)$ & 30.7 & 32.0 & 32.0 & 31.0 \\
Min air temp. $\left({ }^{\circ} \mathrm{C}\right)$ & 12.5 & 13.8 & 13.1 & 13.5 \\
Mean Vapor pressure $(\mathrm{kPa})$ & 1.4 & 1.5 & 1.3 & 1.5 \\
Max. relative humidity $(\%)$ & 91.9 & 92.1 & 87.7 & 93.8 \\
Min. relative humidity $(\%)$ & 22.8 & 21.3 & 18.8 & 26.2 \\
Wind run $\left(\mathrm{km} \mathrm{d}^{-1}\right)$ & 125.7 & 136.7 & 136.4 & 142.3 \\
Solar irradiance $\left(\mathrm{MJ} \mathrm{m} \mathrm{m}^{-2} \mathrm{~d}^{-1}\right)$ & 22.6 & 22.3 & 22.9 & 21.2 \\
Precipitation $(\mathrm{mm})$ & 67.3 & 56.4 & 37.8 & 60.2 \\
\hline
\end{tabular}

676

677

678 
679 Table 3. Daily $E T_{c}$ estimate RMSE (mm day ${ }^{-1}$ ) of each $K_{s}$ and $K_{c b}$ combination in 2012 and 6802013.

\section{$K_{c b}$ estimation method}

\begin{tabular}{lllll} 
Year & $\boldsymbol{K}_{\boldsymbol{s}}$ estimation method & $\begin{array}{l}\text { Canopy } \\
\text { Cover }\end{array}$ & NDVI & Tab \\
\hline \multirow{2}{*}{2012} & CWSI & & & \\
& DANS & 0.93 & $*$ & 0.99 \\
& DACT & 0.71 & $*$ & 0.92 \\
& T $_{\text {cratio }}$ & 0.77 & $*$ & 0.97 \\
& & 0.72 & $*$ & 0.94 \\
\hline \multirow{2}{*}{ CWSI } & & & \\
& DANS & 0.77 & 0.76 & 0.78 \\
& DACT & 0.77 & 0.80 & 0.84 \\
& T & 0.77 & 0.80 & 0.84 \\
\hline
\end{tabular}


683 Table 4. Comparison of basic data required for each $K_{s}$ method tested and associated $E T_{c}$ 684 estimation RMSE.

\begin{tabular}{|c|c|c|c|c|c|}
\hline \multirow{2}{*}{ Category } & \multirow{2}{*}{ Requirement } & \multicolumn{4}{|c|}{$K_{s}$ method } \\
\hline & & CWSI & DANS & DACT & $T_{\text {cratio }}$ \\
\hline \multirow{2}{*}{$\begin{array}{c}\text { Canopy } \\
\text { Temperature }\end{array}$} & Target & $\mathrm{X}$ & $\mathrm{X}$ & $\mathrm{X}$ & $\mathrm{X}$ \\
\hline & Non-Stressed Reference & & $X$ & & $X$ \\
\hline \multirow{3}{*}{ Environmental } & Relative Humidity & $\mathrm{X}$ & & & \\
\hline & Air Temperature & $X$ & & & \\
\hline & Clear Sky & $X$ & $\mathrm{X}$ & $\mathrm{X}$ & $\mathrm{X}$ \\
\hline \multirow{5}{*}{ Pre-Calculation } & $\begin{array}{c}\text { Baselines } \\
\text { (locally calibrated) }\end{array}$ & $X$ & & & \\
\hline & Threshold Temperature & & & $\mathrm{X}$ & \\
\hline & $\begin{array}{l}\text { Scaling Coefficient } \\
\text { (locally calibrated) }\end{array}$ & & $X$ & $\mathrm{X}$ & \\
\hline & Daily $E T_{c}$ RMSE (mm/day) & 0.77 & 0.80 & 0.80 & 0.83 \\
\hline & Daily $E T_{c}$ RMSE (\%) & 14.6 & 15.2 & 15.2 & 15.6 \\
\hline
\end{tabular}

